\title{
Development of Functional Snack Food from Almond Press Cake and Pearl Millet Flour
}

\author{
${\text { Bazila Naseer }{ }^{1(\mathbb{D})} \text {, Vasudha Sharma }}^{1, *(\mathbb{D})}$, Syed Zameer Hussain ${ }^{2(\mathbb{D})}$, Jinku Bora ${ }^{1(\mathbb{D})}$ \\ 1 Department of Food Technology, Jamia Hamdard, New Delhi-110062, India \\ 2 Division of Food Science and Technology, Sher-e-Kashmir University of Agricultural Sciences and Technology \\ (SKUAST) Kashmir, Shalimar-190025, India \\ * Correspondence: vasudhakatwal@gmail.com (V.S.)
}

Scopus Author ID 56235919900

Received: 1.03.2021; Revised: 20.05.2021; Accepted: 23.05.2021; Published: 27.06.2021

\begin{abstract}
Defatted almond cake (DAC), a major by-product of the almond oil industry, was explored in combination with pearl millet (PM) to develop functional snack food using extrusion technology. The optimum extrusion conditions for developing snacks from DAC (20\%) and PM (80\%) flour blends were determined through a numerical optimization technique. The optimized product was evaluated for various quality parameters. The expansion ratio of 3.56 , bulk density $0.11 \mathrm{~g} / \mathrm{cm} 3$, hardness $30.55 \mathrm{~N}$, water absorption index $6.22 \mathrm{~g} / \mathrm{g}$, and water solubility index $14.56 \%$ indicates that its physical characteristics were in the desirable range, while total phenol content of $56.91 \pm 2.09$ (mg GAE/100g), total flavonoid content of $18.29 \pm 0.4(\mathrm{QE} / 100 \mathrm{~g})$ and $\mathrm{DPPH}$ radical scavenging activity (total antioxidant activity) of $89.74 \pm 0.8 \%$ indicates its superior bioactive properties. Production and consumption of such snack types on a large scale can improve the population's nutritional status, besides adding value to the defatted almond cake.
\end{abstract}

Keywords: almond press cake; pearl millet; extrusion; macromolecules; bioactive components; sensory analysis.

(C) 2021 by the authors. This article is an open-access article distributed under the terms and conditions of the Creative Commons Attribution (CC BY) license (https://creativecommons.org/licenses/by/4.0/).

\section{Introduction}

By-product utilization in food processing industries is very poor despite advancements in the food processing sector. A processor sees a by-product as a loss in view of its low scalability and commercial importance. Much research has been conducted in the past on the extraction of bioactive components from different by-products of food processing industries [1]. However, the bioactive components are present in a very minute fraction in these byproducts [2]. Therefore, even after the extraction of these components, the disposal of byproducts remains a big concern and challenge for food industries [3]. Thus, such approaches are not cost-effective and could not be up-scaled successfully so far. The by-products with a good nutritional profile and safe for human consumption can serve as inexpensive raw materials for functional snack foods production [4]. Utilizing these by-products either individually or in combination with other food materials to develop different types of food products seems to be an ideal, sustainable and cost-effective approach for their efficient management and utilization. Defatted almond cake (DAC) is a type of by-product produced in a huge quantity in almond oil extraction units after extracting oil from the almonds. Almond press cake constitutes $43 \%$ of the crushed almonds, while the remaining $57 \%$ goes to oil yield. 
DAC has no commercial value, and its disposal has become a grueling task for these industries. To reduce its disposal burden, it is being used as animal feed [5]. However, DAC is a rich source of proteins $(27.83 \%)$, dietary fiber $(16.12 \%)$, and carbohydrates $(30.15 \%)$ besides containing appreciable amounts of minerals, vitamins, and bioactive compounds [6]. Therefore, its low cost and associated health benefits can be an ideal and logical choice to develop functional snack foods [7]. It has a bland taste; therefore, it needs to be blended with appropriate raw material to improve its taste and develop a balanced food. Pearl millet- a highenergy cereal is a rich source of carbohydrates, protein, fat, vitamins (A and B), calcium, iron, and zinc. Besides that, it also contains potassium, phosphorus, magnesium, zinc, copper, and manganese [8]. Thus, DAC and pearl millet (PM) can complement each other by blending and producing nutritionally balanced and tasty food. Also, both DAC and PM are easily available in India at very low prices. Therefore, one of the cost-effective and sustainable way-outs for their efficient management and value addition can be their utilization in the development of functional snack foods, which help provide remunerative returns to almond oil extraction unit holders farmers involved in pearl millet cultivation. However, it is imperative to use efficient and cost-effective technology to develop such products out of them. Extrusion cooking is an emerging domain, which satisfies all essential criteria, as far as value addition of food and sustainability is concerned. It is an HTST (high-temperature, short-time) low-cost cooking process with many advantages over other processing methods. It is versatile with high output, zero effluent generation, and efficient enzymes and anti-nutritional factors. It also increases the bioavailability of nutrients by increasing starch and protein digestibility. In the last two decades, extrusion cooking has been well studied to produce high protein ready-to-eat snacks from ingredients like soya bean, whey protein concentrate, sorghum, pea flour, etc. [9-13]. However, to the best of our knowledge, no study has been conducted so far on extrusion cooking of defatted almond cake either individually or in combination with pearl millets. Their potential for extrusion cooking is yet to be explored. However, extrusion cooking is a complicated process. Small variations in processing conditions affect the process variables as well as product quality. Extruded snacks' quality characteristics are dependent on the type of extruder, the configuration of the screw, feed moisture content, barrel temperature profile, screw speed and feed rate [14]. Therefore, the present research was undertaken to investigate the effects of different extrusion cooking conditions on product quality to optimize the process protocol for the development of functional snack foods from almond press cake and pearl millet flour.

\section{Materials and Methods}

\subsection{Materials.}

Defatted almond cake (DAC) recommended safe for human consumption by Hamdard Laboratory Manesar, Gurgaon (one of India's leading almond oil extraction units) was brought to the Department of Food Technology, Jamia Hamdard, New Delhi, India. The DAC safety was further ascertained by determining its total plate count (TPC) and mold count (TMC). Both TPC $\left(2 \times 10^{4} \mathrm{CFU} / \mathrm{g}\right)$ and TMC $\left(3.1 \times 10^{2} \mathrm{CFU} / \mathrm{g}\right)$ were found within the safe limits for human consumption [15]. The DAC was ground to flour in a laboratory grinder (Phillips) and sieved through IS 60 stainless steel mesh. The DAC flour, as well as pearl millet (PM) flour (obtained from variety Composite Pusa 383), were packed in zipping lock low-density polyethylene (LDPE) pouches [film thickness: $25 \mu \mathrm{m}$ and density of $0.920 \mathrm{~g} / \mathrm{cm}^{3}$ ] and stored under 
refrigerated conditions $\left(5 \pm 2^{\circ} \mathrm{C}\right)$ for further use. The chemicals and standards used for analysis were purchased from Sigma Aldrich.

\subsection{Proximate composition.}

Standard AOAC (2000) methods were followed to analyze the proximate composition (i.e., moisture, fat, protein, crude fiber, ash, and carbohydrate) of DAC and PM flour samples [16]. Energy value was estimated by bomb colorimeter (Model C5000, Germany). Standard serial dilution method using nutrient agar and potato dextrose agar as growth media was employed to determine TPC and TMC.

\subsection{Formulation of feed proportion.}

Six blends viz., 100:0, 90:10, 85:15, 80:20, 75:25, and 70:30 were formulated from pearl millet (PM) and defatted almond cake (DAC) flour samples, respectively. Preliminary trials were conducted to determine the desired screw speed, barrel temperature, and feed moisture content to develop extruded snacks from these blends. Based on these trials, $20 \%$ (dry basis) feed moisture content, $120^{\circ} \mathrm{C}$ barrel temperature, and $420 \mathrm{rpm}$ screw speed were found most suitable conditions to develop quality snacks. All the six formulations were thus extruded under these constant extrusion conditions. The extrudates obtained after that were cooled under ambient conditions $\left(25 \pm 2^{\circ} \mathrm{C}\right)$ and subjected to sensory evaluation. Based on the highest sensory score of snacks, PM and DAC flour blend was chosen for further study.

\subsection{Extrusion cooking.}

A co-rotating twin-screw extruder (Basic Technology Pvt. Ltd., Kolkata, India) having a length to diameter ratio (L/D) of $8: 1$ and a circular die of $3 \mathrm{~mm}$ diameter was used for extrusion cooking. The temperature was maintained as $60^{\circ} \mathrm{C}$ and $80^{\circ} \mathrm{C}$ at the first and second zone, respectively, throughout the experiment, while at the last barrel zone, the temperature was varied as per the experimental design (Table 1). The blend ratio of PM and DAC flour as formulated previously was kept constant during the entire experimentation. The sample size for each experimental run was one $\mathrm{kg}$, and the moisture content of each sample was adjusted by adding water (as per the experimental design, Table 1) followed by mixing in a Brabender (Germany) planetary mixer. The conditioned samples were kept in low-density polyethylene (LDPE) bags (film thickness: $25 \mu \mathrm{m}$ and density of $0.920 \mathrm{~g} / \mathrm{cm}^{3}$ ) for $12 \mathrm{~h}$ before extrusion. Extrusion cooking of the conditioned samples was done as per the conditions given in Table 1. The developed extruded snacks collected in clean stainless-steel trays were cooled under ambient conditions $\left(25 \pm 2^{\circ} \mathrm{C}\right)$ and packed in low-density polyethylene (LDPE) bags (film thickness: $25 \mu \mathrm{m}$ and density of $0.920 \mathrm{~g} / \mathrm{cm}^{3}$ ) for further analysis.

Table 1. Box Behnken experimental design of extrusion conditions and product responses.

\begin{tabular}{|c|c|c|c|c|c|c|c|c|}
\hline \multirow[t]{2}{*}{ Run } & \multicolumn{4}{|c|}{ Extrusion conditions } & \multicolumn{4}{|c|}{ Product responses } \\
\hline & $\begin{array}{c}\text { FM } \\
\text { (\% wet } \\
\text { basis) } \\
\end{array}$ & $\underset{(\mathbf{r p m})}{\mathbf{S S}}$ & BT $\left({ }^{\circ} \mathbf{C}\right)$ & ER & BD $\left(\mathrm{g} / \mathrm{cm}^{3}\right)$ & Hardness (N) & WAI (g/g) & WSI (\%) \\
\hline 1 & 23.00 & 350.00 & 110.00 & 3.243 & 0.146 & 29.819 & 6.135 & 9.540 \\
\hline 2 & 18.00 & 450.00 & 110.00 & 3.153 & 0.122 & 37.108 & 5.815 & 14.884 \\
\hline 3 & 23.00 & 400.00 & 120.00 & 3.300 & 0.128 & 27.892 & 6.291 & 15.646 \\
\hline 4 & 20.50 & 400.00 & 110.00 & 3.153 & 0.128 & 33.924 & 5.968 & 13.592 \\
\hline 5 & 18.00 & 400.00 & 100.00 & 3.311 & 0.133 & 32.403 & 5.785 & 15.668 \\
\hline 6 & 18.00 & 350.00 & 110.00 & 2.941 & 0.156 & 52.794 & 5.860 & 12.239 \\
\hline 7 & 20.50 & 400.00 & 110.00 & 3.028 & 0.136 & 36.033 & 5.985 & 14.438 \\
\hline
\end{tabular}




\begin{tabular}{l|l|l|l|l|l|l|l|l}
\hline \multirow{2}{*}{ Run } & \multicolumn{9}{c}{ Extrusion conditions } & \multicolumn{5}{c}{ Product responses } \\
\cline { 2 - 10 } & $\begin{array}{c}\text { FM } \\
\text { \% wet } \\
\text { basis) }\end{array}$ & $\begin{array}{c}\text { SS } \\
(\mathbf{r p m})\end{array}$ & $\mathbf{B T}\left({ }^{\circ} \mathbf{C}\right)$ & $\mathbf{E R}$ & $\mathbf{B D}\left(\mathbf{g} / \mathbf{c m}^{\mathbf{3}}\right)$ & Hardness (N) & WAI (g/g) & WSI (\%) \\
\hline 8 & 20.50 & 450.00 & 100.00 & 3.287 & 0.123 & 29.520 & 5.936 & 15.740 \\
\hline 9 & 18.00 & 400.00 & 120.00 & 3.236 & 0.139 & 32.463 & 5.891 & 15.000 \\
\hline 10 & 20.50 & 400.00 & 110.00 & 3.034 & 0.133 & 40.084 & 6.126 & 13.613 \\
\hline 11 & 23.00 & 450.00 & 110.00 & 3.161 & 0.125 & 34.172 & 6.315 & 15.900 \\
\hline 12 & 20.50 & 350.00 & 100.00 & 3.312 & 0.151 & 32.903 & 5.928 & 8.632 \\
\hline 13 & 23.00 & 400.00 & 100.00 & 3.419 & 0.137 & 30.321 & 6.172 & 13.209 \\
\hline 14 & 20.50 & 400.00 & 110.00 & 3.226 & 0.136 & 37.573 & 6.133 & 9.615 \\
\hline 15 & 20.50 & 350.00 & 120.00 & 3.243 & 0.152 & 37.901 & 6.275 & 10.279 \\
\hline 16 & 20.50 & 400.00 & 110.00 & 3.022 & 0.135 & 34.473 & 6.109 & 12.672 \\
\hline 17 & 20.50 & 450.00 & 120.00 & 3.559 & 0.107 & 31.706 & 6.256 & 14.038
\end{tabular}

Note: FM indicates feed moisture, SS indicates screw speed, BT indicates barrel temperature, ER indicates expansion ratio, BD indicates bulk density, WAI indicates water absorption index, and WSI indicates water solubility index. Data given are mean values of 3 measurements.

\subsection{Experimental design and process optimization.}

A 3-level-3-factor Box-Behnken design used in the study resulted from 17 experimental runs (Table 1). The independent variables considered were barrel temperature, screw speed, and feed moisture, while the dependent variables were expansion ratio (ER), bulk density (BD), hardness $(\mathrm{H})$, water solubility index (WSI), and water absorption index (WAI). The levels of the independent variables were selected, augmenting the outcome of preliminary experimental trials. To fit the experimental data, second-order polynomial models were established for each response. Analysis of variance (ANOVA) and multiple regression analysis was conducted to test the significance of the variables' linear, quadratic, and interaction effects on various quality parameters. Process optimization was done by Design Expert 9 (Stat ease Inc, Minneapolis, MN, USA) through numerical optimization technique. The optimum condition criteria applied for numerical optimization were maximizing ER, WAI, WSI, and minimizing BD and hardness.

\subsection{Physical properties analyzed.}

ER was calculated as the ratio of extrudate thickness and the die diameter using a digital Vernier caliper of $0.001 \mathrm{~mm}$ accuracy. BD of extrudates was measured using the volumetric displacement method. Hardness was measured by a crushing method using a Texture Analyzer (TA-XT2i, Stable Micro Systems Ltd., UK). A P75 compression probe attached to a $25 \mathrm{~kg}$ load cell was employed to measure the extrudates' hardness. Force-time curve was recorded, and the peak force in Newton $(\mathrm{N})$ was taken as a measure of Hardness $(\mathrm{H})$ [17].WAI and WSI were determined as per the below-mentioned formulae [18].

$$
\begin{aligned}
& W A I(g / g)=\frac{\text { Weight gain by gel }}{\text { Dryweightofextrudate }} \\
& W S I(\%)=\frac{\text { Weightofdissolved solids in supernatant }}{\text { Weightofdrysolids }} \times 100
\end{aligned}
$$

\subsection{Determination of bioactive components.}

\subsubsection{Preparation of extracts.}

Total phenolics and flavonoids were determined as per the methods described by Zhang et al. (2018) [19]. $2 \mathrm{~g}$ of flour samples were mixed with $80 \%$ chilled acetone $(50 \mathrm{ml})$, and the mixture was homogenized. The resulting homogenate was centrifuged at $2500 \mathrm{rpm}$ for $10 \mathrm{~min}$. 
Extraction was again done for precipitate obtained after centrifugation, and the supernatants were combined and concentrated. $10 \mathrm{~mL}$ of methanol was used for the reconstitution of extracts. Bound phenolics were extracted by hydrolyzing the residue obtained after extraction of free phenolics with $2 \mathrm{M} \mathrm{NaOH}(40 \mathrm{~mL})$ for 1 hour with continuous shaking at room temperature. Concentrated $\mathrm{HCl}$ was added to neutralize the mixture until $\mathrm{pH} 2$ was obtained. The mixture was treated with hexane to remove lipids. The resulting mixture was extracted with ethyl acetate 5-6 times, and combined fractions of solvent were dried at $45^{\circ} \mathrm{C}$. Distilled water (up to $10 \mathrm{ml}$ ) was added to extracts for reconstitution, and all the prepared extracts were stored at $-4^{\circ} \mathrm{C}$ till further analysis.

\subsubsection{Determination of Total Phenolic Content (TPC).}

The amount of total phenolics in the extract was determined with the Folin Ciocalteau reagent. Gallic acid was used as a standard, and the total phenolics were expressed as $\mathrm{mg} / 100 \mathrm{~g}$ gallic acid equivalents (GAE) using the spectrometric method [20].

\subsubsection{Determination of the Total Flavonoid Content (TFC).}

The aluminum chloride method was used for flavonoid determination. Quercetin was used as standard, and flavonoid contents were measured as quercetin equivalent [20].

\subsubsection{2-diphenyl-1-picrylhydrazyl (DPPH) radical-scavenging activity (Antioxidant} activity).

The DPPH radical-scavenging activity was calculated as a percentage of DPPH discoloration using the following equation [21].

$D P P H$ radical scavenging activity $=\frac{\text { Absorbance }_{D P P H} \text { solution }}{\text { Absorbance }_{\text {extract solution }}} \times 100$

\subsection{Sensory evaluation of the extrudates.}

A panel of 10 trained judges evaluated the extruded snacks randomly for different sensory attributes viz., color, texture, flavor, and mouthfeel, on a 9-point hedonic scale. Prior to sensory evaluation, the judges acquainted themselves with the use of the rating method, terminology for each attribute, and sensory characteristics [22,23]. Panelists rinsed their mouths in between the evaluation of different samples. The overall acceptability score was calculated as the average of the sensory score obtained for various parameters [24].

\subsection{Statistical analysis.}

Bioactive components and sensory attributes were evaluated in triplicates, and average values were used for statistical analysis. To assess the statistical validity for different parameters between raw material and final product, the student's t-test was employed at a 5\% level of significance using SPSS software.

\section{Results and Discussion}

\subsection{Proximate composition of raw material used.}

The proximate composition of Defatted almond cake (DAC) and Pearl millet (PM) flour samples is depicted in Table 2. Results indicated that DAC could be a major contributor of 
protein and fat, whereas PM can serve as a major carbohydrate source. Ash and the energy value of DAC were also significantly $(\mathrm{p}<0.05)$ higher than PM. However, there was no significant difference in crude fiber content of DAC and PM. An almost similar proximate composition of defatted almond flour and pearl millet flour has been reported by Siqueira et al. (2015) and Nambair et al. (2011) as well [6, 8].

Table 2. Proximate composition of ingredients.

\begin{tabular}{|c|c|c|}
\hline Constituents & DAF & PMF \\
\hline Moisture (\%) & $8.95^{\mathrm{a}} \pm 1.21$ & $10.23^{\mathrm{b}} \pm 0.09$ \\
\hline Crude Fat $(\%)$ & $10.04^{\mathrm{a}} \pm 0.05$ & $4.97^{b} \pm 0.06$ \\
\hline $\operatorname{Ash}(\%)$ & $6.14^{\mathrm{a}} \pm 0.37$ & $1.61^{\mathrm{b}} \pm 0.01$ \\
\hline Crude Protein $(\%)$ & $35.83^{\mathrm{a}} \pm 0.83$ & $9.95^{\mathrm{b}} \pm 0.07$ \\
\hline Carbohydrates (\%) & $36.69^{\mathrm{a}} \pm 2.12$ & $71.09^{b} \pm 0.14$ \\
\hline Crude fibre $(\%)$ & $2.35^{\mathrm{a}} \pm 0.21$ & $2.15^{\mathrm{a}} \pm 0.07$ \\
\hline $\begin{array}{l}\text { Energy value } \\
\text { (Kcal/100g) }\end{array}$ & $380.44^{\mathrm{a}} \pm 0.6$ & $368.89^{\mathrm{b}} \pm 0.5$ \\
\hline
\end{tabular}

Data given is the mean value of triplicate readings \pm standard deviation (SD). Mean values in the rows with different superscripts are significantly different at $\mathrm{p} \leq 0.05$. DAF-Defatted Almond Flour; PMF-Pearl Millet

Flour.

\subsection{Sensory Evaluation of extruded snacks made from different formulations of DAC and}

$P M$.

All the snacks developed from the blends containing more than 20\% DAC had hard textures and were bitter in taste, reducing their flavor, texture, and mouthfeel scores (Figure 1). The tannins present in DAC might have imparted bitterness [6] to these snacks, and at the same time, its high fat and protein content may have restricted the expansion of snacks. Furthermore, the color was also recorded lower in these snacks. Since defatted almond flour (DAF) is brownish; therefore its high incorporation percentage may have impaired the appearance of snacks. Flavor, mouthfeel, texture, and color scores were also recorded lower in all three snack types, having a lesser percentage of DAC (from 0 to 15\%) than the snacks developed from the blend containing 20\% DAC, and 80\% PM.

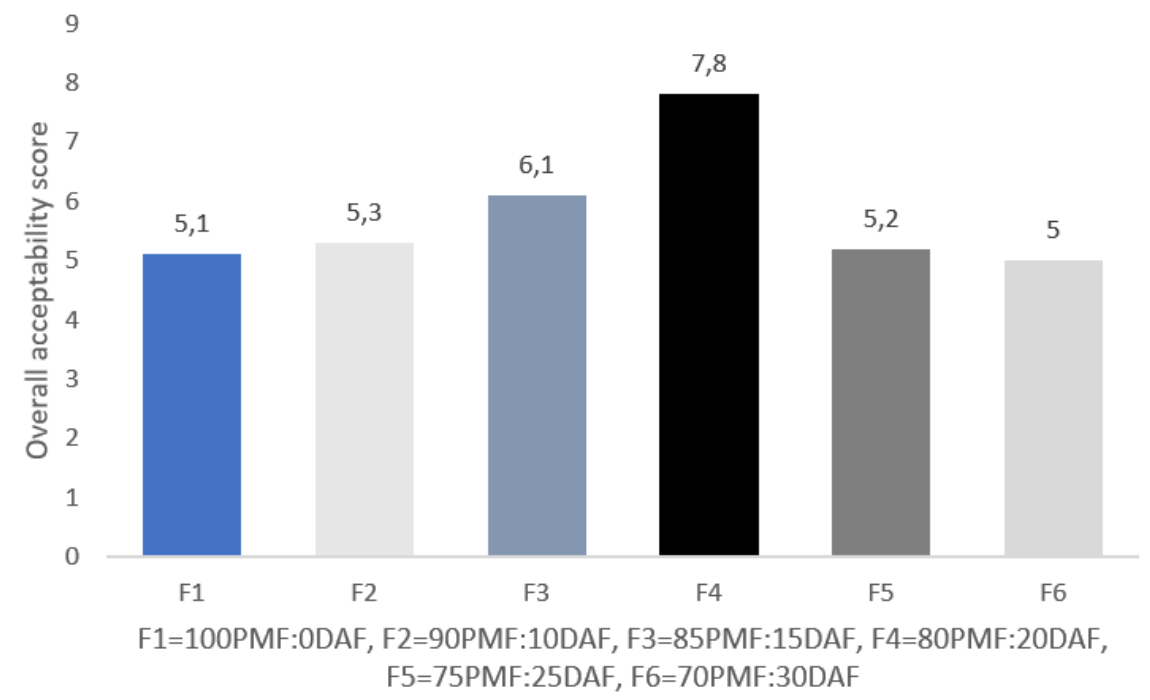

Figure 1. Overall acceptability of extruded snacks developed from different blend formulations of defatted almond cake and pearl millet flour.

The snacks made from 100\% PM flour had a somewhat bland and unpleasant taste besides having poor texture. Correspondingly, up to $20 \%$ incorporation of DAF, flavor, color, texture, and mouthfeel scores increased. Small fat percentage facilitates steady extrusion 
without excessive dilution effect on starch, improving the texture and mouthfeel of extruded snacks. Among all extruded snacks developed from DAC and PM's six different formulations, the highest overall acceptability score (7.8 on a 9-point scale) (Figure 1) was exhibited by the snacks developed from the blend containing 20\%, DAC, and 80\% PM. Therefore, based on the overall acceptability score, this blend formulation was selected as feed proportion during the entire study to investigate the effects of extrusion conditions and moisture content on different quality characteristics of almond-pearl millet (APM) based snacks.

\subsection{Impact of various extrusion conditions on physical properties of the extrudate.}

\subsubsection{A fit of the model.}

The models' significance and adequacy developed for all dependent variables were tested using the ANOVA technique (Table 2). All the developed models were highly significant $(\mathrm{p}<0.001)$ with a high coefficient of determination $\left(\mathrm{R}^{2} \geq 0.839\right)$. Lack of fit was non-significant in all the models, which further confirmed their validity. In all the model parameters, predicted and adjusted $\mathrm{R}^{2}$ values were in reasonable agreement, implying that all second-order polynomial models correlated well with the measured data. A highly desirable adequate precision range (9.465-17.834) was observed in all the models, suggesting the adequacy of model discrimination in all the parameters. $\mathrm{CV}$ range of $1.28-5.80 \%$ demonstrates the accuracy and reproducibility of models in all the dependent variables.

Table 3 Analysis of variance for the fit of experimental data to response surface models.

\begin{tabular}{l|c|c|c|c|c} 
Regression & ER & BD & Hardness & WAI & WSI \\
\hline \multicolumn{1}{c|}{ R-squared } & 0.8981 & 0.9405 & 0.9483 & 0.8391 & 0.9643 \\
\hline Adjusted R-squared & 0.7672 & 0.9048 & 0.8819 & 0.8020 & 0.9183 \\
\hline Predicted R-squared & 0.7531 & 0.7760 & 0.8277 & 0.7155 & 0.8515 \\
\hline Adequate precision & 9.465 & 17.834 & 17.094 & 16.336 & 15.802 \\
\hline C.V.\% & 2.24 & 2.83 & 5.80 & 1.28 & 4.03 \\
\hline Lack of fit & NS & NS & NS & NS & NS \\
BD = bulk density WAI = Water absorption index, WSI= Water solubility index.
\end{tabular}

3.3.2. Expansion ratio and bulk density.

Extruded snacks having a high expansion ratio (ER) and low bulk density (BD) are always preferred by the consumers owing to their puffiness [14]. The ER and BD of different extruded snacks varied from 2.941 to 3.559 and 0.107 to $0.156 \mathrm{~g} / \mathrm{cm}^{3,}$ respectively. The highest ER (3.559) and lowest BD $\left(0.107 \mathrm{~g} / \mathrm{cm}^{3}\right)$ were recorded at an experimental run 17 , having the highest barrel temperature $\left(120^{\circ} \mathrm{C}\right)$ and screw speed $(450 \mathrm{rpm})$, when the moisture content of the feed material was in the intermediate range (20.50\%) (Table 1). The fitted regression equation for ER and BD are depicted below, where A is feed moisture, B is screw speed, and $\mathrm{C}$ is barrel temperature.

$\mathrm{ER}=+3.09+0.077 \mathrm{~A}+0.032 \mathrm{~B}^{2}+0.22 \mathrm{C}^{2}$
$\mathrm{BD}=+0.13-0.00175 \mathrm{~A}-0.016 \mathrm{~B}-0.017 \mathrm{C}-0.0042 \mathrm{BC}$

Figure 2A shows the response surface plot for ER as a function of FM and SS, while Figure 2B shows the response surface plot for ER as a function of FM and BT. Likewise, Figure $2 \mathrm{C}$ shows the response surface plot for BD as a function of FM and SS, while Figure 2D shows the response surface plot for BD as a function of FM and BT. All three independent variables exhibited significant positive relationships with ER and negative with BD (Eq. 4 and 5). 
However, the effect of barrel temperature (C) was most dominant on both the dependent variables, followed by screw speed (B) and moisture content (A) (Eq. 4 and 5). At higher moisture content, the water flashes off as steam during extrusion cooking [25], increasing the expansion and reducing the bulk density of extruded snacks. Higher moisture enhances the gelatinization of starch during extrusion cooking, which decreases the melt viscosity and enhances the bubble formation in the cell wall, due to which expansion is increased while density is reduced in snacks [26]. The higher barrel temperature leads to super-heating of the water molecules, which justifies the prominent increase in ER and decrease in BD with the increase in barrel temperature [27]. Higher screw speed leads to a higher shearing force, which reduces the bond strength and chain length of starch and protein molecules, reducing extrudates' density through easy expansion [28]. Higher screw speed leads to the higher breakdown of the structure during extrusion cooking [28] which justifies the inverse relationship of screw speed with BD. These findings are in agreement with those of Altan et al. (2009) and Hashemi et al. (2017) for ready-to-eat extruded snacks prepared from barleytomato pomace blends and defatted almond and cornflour, respectively $[29,30]$.

\subsubsection{Hardness.}

Consumers usually prefer snacks having lower hardness due to their lightness and crispy texture [14]. The hardness of different extruded snacks ranged from 27.891 to $52.794 \mathrm{~N}$. The lowest hardness $(27.891 \mathrm{~N})$ was recorded in snacks extruded through experimental run 3 , having the highest moisture content $(23.00 \%)$ and barrel temperature $\left(120^{\circ} \mathrm{C}\right)$ with intermediate screw speed (400 rpm).
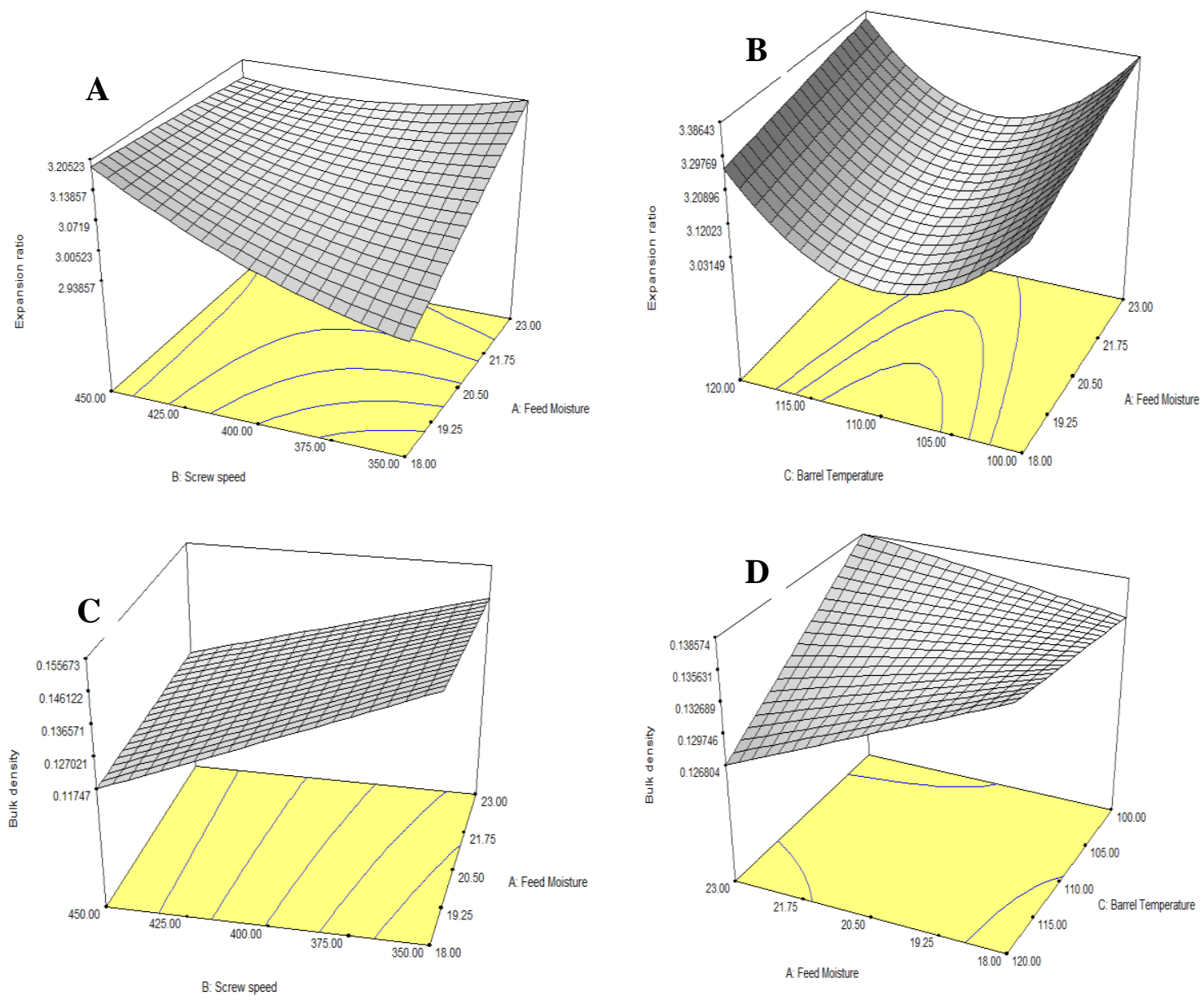

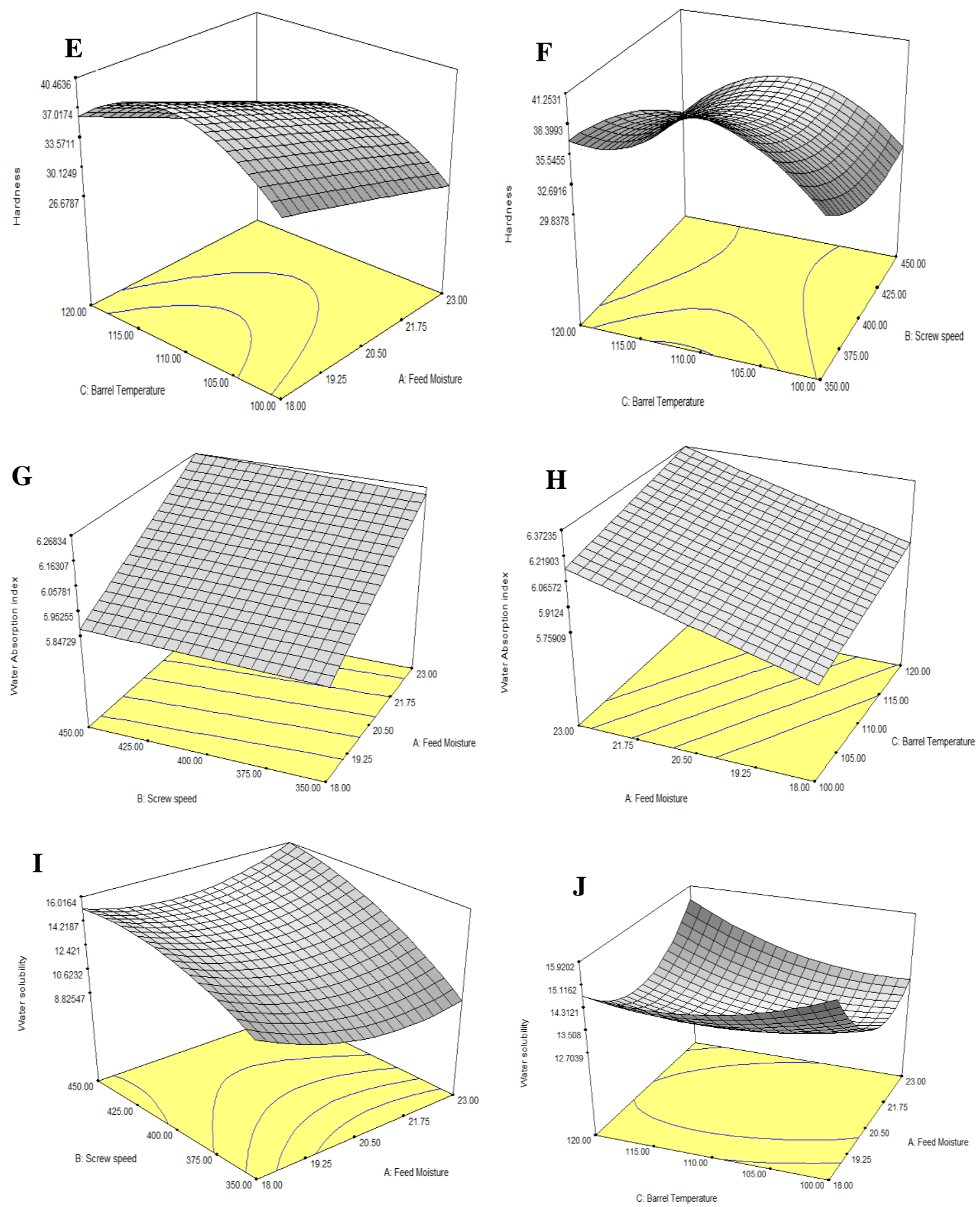

While as highest hardness $(52.794 \mathrm{~N})$ was recorded in snacks developed from low moisture feed material $(18.0 \%)$ at the lowest screw speed $(350 \mathrm{rpm})$ and intermediate barrel temperature $\left(110^{\circ} \mathrm{C}\right)$ (Table 1$)$. The fitted regression equation for hardness is depicted below.

$$
\text { Hardness }=+36.42-5.01 \mathrm{~A}-2.18 \mathrm{~B}+1.98 \mathrm{C}-5.59 \mathrm{C}^{2}
$$

Figure $2 \mathrm{E}$ shows the response surface plot for hardness as a function of FM and BT, while Figure 2F shows the response surface plot for hardness as a function of BT and SS. 


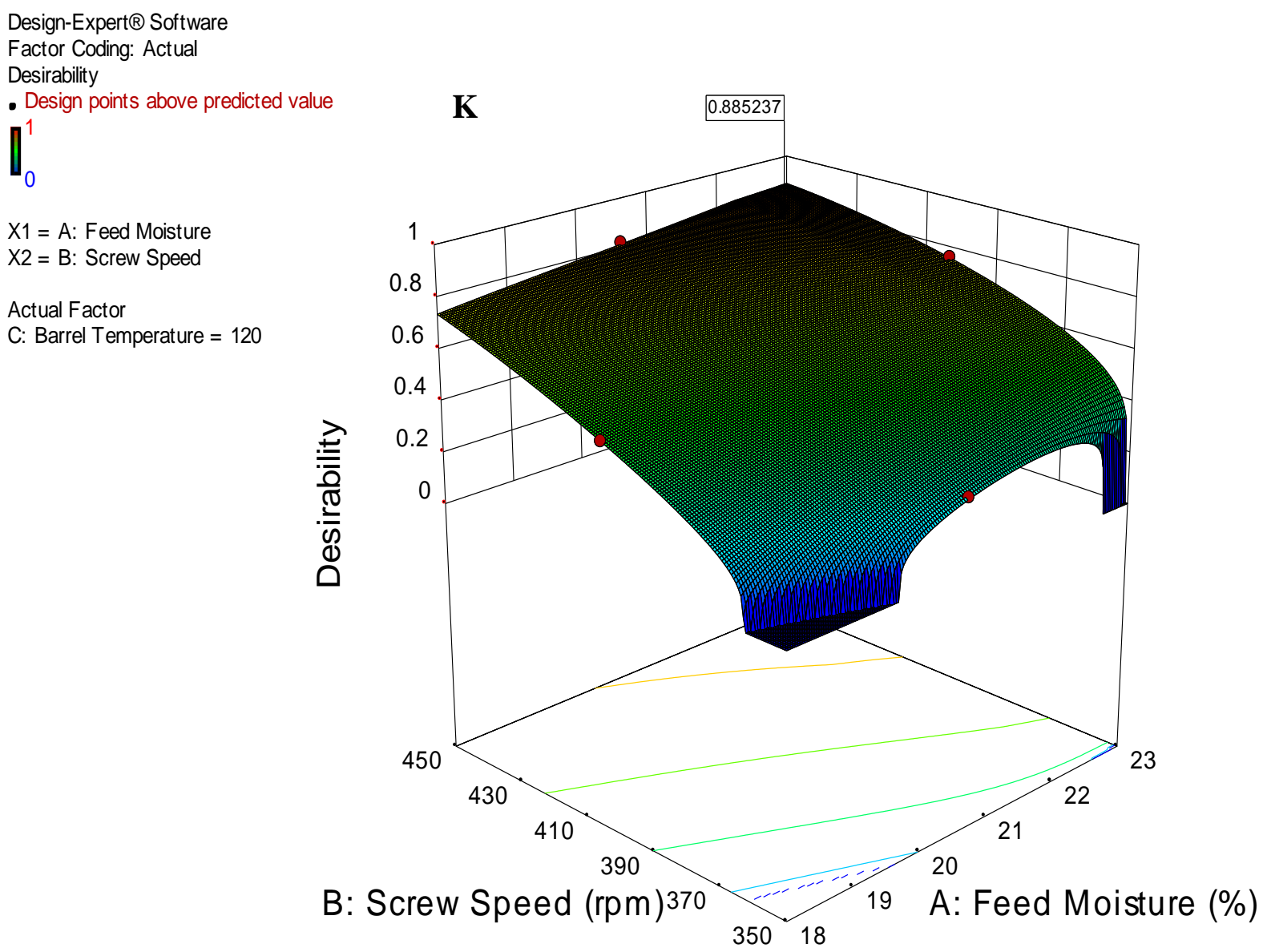

Figure 2. (A) response surface plot for ER as a function of FM and SS; (B) response surface plot for ER as a function of FM and BT; (C) response surface plot for BD as a function of FM and SS; (D) response surface plot for BD as a function of FM and BT; (E) response surface plot for $\mathrm{H}$ as a function of $\mathrm{FM}$ and BT; (F) response surface plot for $\mathrm{H}$ as a function of BT and SS; (G) response surface plot for WAI as a function of FM and SS; (H) response surface plot for WAI as a function of FM and BT; (I) response surface plot for WSI as a function of FM and SS; (J) response surface plot for WSI as a function of FM and BT; (K) Desirability plot. Note: FM indicates feed moisture, SS indicates screw speed, BT indicates barrel temperature, ER indicates expansion ratio, $\mathrm{BD}$ indicates bulk density, WAI indicates water absorption index and WSI indicates water solubility index.

Both moisture content (A) and screw speed (B) exhibited significant inverse linear relationships with hardness, while as, the linear relationship between barrel temperature and hardness was positive, and their quadratic relationship was negative. Out of all effects, the quadratic effect of barrel temperature $\left(\mathrm{C}^{2}\right)$ was most dominant, followed by the linear effect of moisture content (A) (Eq.6). Lesser density snacks having porous structures are formed at higher moisture content during extrusion cooking [31] which consumers usually prefer due to their light and crispy texture. The lesser hardness of extruded snacks at higher moisture content was also reported by similar researchers $[31,32]$. With the increase in screw speed hardness of extrudates was found to decrease (Eq.6). The higher screw speed reduces the dough's melt viscosity, which favors the bubble growth formation, leading to the production of thin cell walled low-density extrudates [27]. During extrusion cooking, the higher barrel temperature causes lateral expansion, which reduces the extrudates' density [27]. It has been very well documented that expanded products with lesser BD are less dense [14]. In the present study, the less hardness of the snacks obtained at higher levels of moisture content, screw speed, and barrel temperature was also in line with the lesser BD obtained at higher levels of these variables. Similar results were reported for hardness by Altan et al. (2008) in barley-tomato pomace-based extrudates [29]. 


\subsubsection{Water absorption and Water solubility indices (WAI and WSI).}

Water absorption represents the amount of water immobilized by the extrudates, while water solubility represents the amount of small molecules solubilized in water [32]. These indices (WAI and WSI) can estimate the snacks' functional characteristics and the material behavior upon further processing besides providing enlightenment about the physic-chemical changes of the biopolymers during extrusion [32] and are thus, important quality attributes of extruded snacks. The WAI and WSI of different extruded snacks varied from 5.785 to $6.315 \mathrm{~g} / \mathrm{g}$ and 8.632 to $15.90 \%$, respectively. The fitted regression equation for WAI and WSI are depicted below, where A is feed moisture, B is screw speed, and C is barrel temperature

$$
\begin{aligned}
& \mathrm{WAI}=+6.06+0.20 \mathrm{~A}+0.35 \mathrm{~B}+0.01 \mathrm{C} \\
& \mathrm{WSI}=+13.50-0.67 \mathrm{~A}+2.25 \mathrm{~B}-0.49 \mathrm{C}+0.89 \mathrm{AB}-0.97 \mathrm{~B}^{2}
\end{aligned}
$$

Figure $2 \mathrm{G}$ shows the response surface plot for WAI as a function of FM and SS, while Figure2H shows the response surface plot for WAI as a function of FM and BT. Likewise, Figure 2I shows the response surface plot for WSI as a function of FM and SS, while Figure $2 \mathrm{~J}$ shows the response surface plot for WSI as a function of FM and BT. All three independent variables demonstrated significant positive relationships with WAI. However, moisture content (A) and barrel temperature (C) had inverse relationships with WSI, while screw speed had a positive linear effect (B) as well as a negative quadratic $\left(\mathrm{B}^{2}\right)$ effect on WSI (Eq. 7 and 8). The coefficients of the equation (7 and 8) indicate that the positive linear effect of screw speed (B) was most dominant on both the dependent variables, followed by the positive linear effect of moisture content (A) in the case of WAI and negative linear effect in case of WSI. The data depicted in Table 1 indicates that the highest WAI $(6.315 \mathrm{~g} / \mathrm{g})$ and WSI $(15.90 \%)$ were recorded at an experimental run 11, having the highest screw speed $(450 \mathrm{rpm})$ and feed moisture content $(23 \%)$ with an intermediate level of barrel temperature $\left(110^{\circ} \mathrm{C}\right)$. Although moisture content had a negative relationship with WSI, the positive interaction of $\mathrm{AB}$ indicates that the positive effect of screw speed was dominant over the negative effect of moisture content. During extrusion, cooking water has a plasticizing effect that facilitates starch's gelatinization under high-temperature conditions that might have enhanced the water absorption of starch granules [33]. In addition, non-covalent linkages with polypeptide chains may also have positioned in extrudates under high moisture conditions due to the high protein percentage [34] of DAC, which may have reduced the water solubility and supplemented the higher water absorption of snacks. With the increase in screw speed, both water absorption and water solubility were increased (Eq. 7 and 8). Higher screw speed causes fragmentation of macromolecules that expose hydrophilic sites to water due to increased expansion [35], increasing the WAI. Furthermore, the surface area is also increased due to the breakdown of molecules, which enhances their water solubility [29]. The barrel temperature is directly correlated with WAI and inverse with WSI (Eq. 7 and 8). High temperature during extrusion cooking favors the electrostatic interactions and reduces the disulfide linkages [36], which may have reduced the water solubility capacity and increased the water immobilization capacity of extrudates. Similar results have been reported by Kumar et al. (2018); Alam et al. (2014) for WSI and WAI in extrusion-related studies, respectively [37-38]. 


\subsection{Extrusion process optimization and validation.}

Response Surface Methodology was used to optimize the feed moisture content (FM), screw speed (SS), and barrel temperature (BT) for the development of defatted almond press cake (DAC) incorporated pearl millet (PM) based extruded snacks. The optimal solution selected based on the highest desirability value 0.886 (Figure $2 \mathrm{~K}$ ) suggested that $23 \% \mathrm{FM}, 450$ rpm SS and $120^{\circ} \mathrm{C} \mathrm{BT}$ are the most suitable condition to develop quality snacks from the blend of DAC (20\%): PM (80\%) through extrusion technology. The values predicted by Design Expert 9 (Stat ease Inc, Minneapolis, MN, USA) for ER, BD, hardness, WAI, and WSI were $3.451,0.11 \mathrm{~g} / \mathrm{cm}^{3}, 31.43 \mathrm{~N}, 6.38 \mathrm{~g} / \mathrm{g}$, and $14.93 \%$, respectively. The extruded snacks developed after following the optimized conditions exhibited the values for ER, BD, hardness, WAI, and WSI as $3.566,0.113 \mathrm{~g} / \mathrm{cm}^{3}, 30.55 \mathrm{~N}, 6.22 \mathrm{~g} / \mathrm{g}$, and $14.56 \%$, respectively. The predicted and actual values of all the quality attributes of snacks were almost similar, with a variation of $\leq$ $3.2 \%$. More or less similar values as recorded in the present study were also reported by Omwamba and Mahungu (2014), Keawpeng et al. (2014), Divate et al. (2015), and Kumar et al. (2015) in various protein-rich extruded snacks [12,37,39,40,].

\subsection{Characterization of almond-pearl millet (APM) based snacks.}

\subsubsection{Proximate composition.}

Optimized conditions were followed to develop extruded snacks from flour blend (80:20, PM: DAC) to compare their proximate composition. Except for protein and crude fiber, all other APM snacks and flour blend attributes were significantly different (Table 4). The moisture content $(6.03 \%)$ of APM snacks was significantly $(\mathrm{p}<0.05)$ lower than the flour blend $(23 \%)$. The high temperature and pressure generated during extrusion cooking flashes off the moisture from the feed material and propels out the low moisture snacks through the die. The crude fat content was decreased significantly from $6.20 \%$ in flour blend to $5.89 \%$ in APM snacks. In the case of high-fat materials (> 5\%), part of the lipid fraction is lost at the die section due to high barrel temperature. The formation of complexes between lipids and amylose and or proteins can explain extrudates' reduced fat content [14]. The high ash content $(1.98 \%)$ of blend flour demonstrates its high mineral content. Siqueira et al. (2015) and Nambair et al. (2011) have also reported that almonds and pearl millets have appreciably higher mineral content, especially calcium and magnesium $[6,8]$. During extrusion cooking, the ash content was further increased to $(2.17 \%)$ which can be related to the heat-stable nature of minerals besides moisture loss during extrusion [14]. Furthermore, high temperature during extrusion destroys polyphenols and reduces the phytate content, which reduces the involvement of minerals in insoluble complex formation [41] that eventually may have led to an increase in ash content. In addition to that, dietary fiber components within the feed material are also reorganized during extrusion cooking that changes their chelating properties [42], which can explain the higher ash content of extruded snacks than that of the flour blend. The carbohydrate content was significantly higher in APM snacks (68.27\%) as compared to flour blend (51.23\%), which can be attributed to moisture loss during extrusion cooking [14] since the difference method was adopted to determine the total carbohydrate content. Energy value of 387.89 $\mathrm{Kcal} / 100 \mathrm{~g}$ was recorded in APM snacks which were significantly $(\mathrm{p}<0.05)$ higher than that of flour blend $322.64 \mathrm{Kcal} / 100 \mathrm{~g}$. During extrusion cooking, part of the indigestible complex carbohydrates gets converted into soluble carbohydrates and simple sugars [42], which justifies 
extruded snacks' higher energy value than feed material. The proximate composition of APM snacks was comparable to that of extruded snacks developed from rice-sorghum-soybean by Shadan et al. (2014) and cereal-pulses by Omwamba and Mahungu (2014), respectively [11, 12].

Table 4. Physicochemical and bioactive characteristics of composite flour blend and optimized extrudate almond- pearl millet (APM) based snack.

\begin{tabular}{l|l|l} 
Properties & Composite Flour blend & APM snacks \\
\hline Moisture (\%) & $23.00^{\mathrm{a}} \pm 0.35$ & $6.03^{\mathrm{b}} \pm 0.02$ \\
\hline Crude fat (\%) & $6.20^{\mathrm{a}} \pm 0.04$ & $5.89^{\mathrm{b}} \pm 0.03$ \\
\hline Ash (\%) & $1.98^{\mathrm{a}} \pm 0.3$ & $2.17^{\mathrm{b}} \pm 0.2$ \\
\hline Crude protein (\%) & $15.48^{\mathrm{a}} \pm 0.36$ & $15.45^{\mathrm{a}} \pm 0.15$ \\
\hline Carbohydrate \% & $51.23^{\mathrm{a}} \pm 0.12$ & $68.27^{\mathrm{b}} \pm 0.09$ \\
\hline Crude fiber (\%) & $2.11^{\mathrm{a}} \pm 0.56$ & $2.19^{\mathrm{a}} \pm 0.07$ \\
\hline Energy value (Kcal/100g) & $322.64^{\mathrm{a}} \pm 0.7$ & $387.89^{\mathrm{b}} \pm 0.5$ \\
\hline TPC (mg /100g) & $60.34^{\mathrm{a}} \pm 1.5$ & $56.91^{\mathrm{b}} \pm 2.09$ \\
\hline TFC (mg /100g) & $20.65^{\mathrm{a}} \pm 0.14$ & $18.29^{\mathrm{a}} \pm 0.4$ \\
\hline $\begin{array}{l}\text { Antioxidant activity (DPPH radical } \\
\text { scavenging activity) } \%)\end{array}$ & $89.93^{\mathrm{a}} \pm 0.66$ & $89.74^{\mathrm{a}} \pm 0.8$ \\
\hline Overall acceptability score & - & \\
\hline Composte & & $8.2 \pm 0.55^{*}$
\end{tabular}

Composite flour comprises $20 \%$ defatted almond cake flour and $80 \%$ pearl millet flour; APM snacks comprise $20 \%$ defatted almond cake flour and $80 \%$ pearl millet flour; Data given is mean of triplicate readings \pm SD. Mean values in the rows with different superscripts are significantly different at $p \leq 0.05$. *Data given is mean of sensory evaluation done by 10 trained panelists; $\mathrm{TPC}=$ total phenolic content and $\mathrm{TFC}=$ total flavonoid content.

\subsubsection{Total phenolic and flavonoid contents.}

Bioactive compounds with high antioxidant potential and protective effects are present in significant proportions in pearl millet and almond. They are considered ideal raw material candidates to focus on developing functional foods [43, 44]. Total phenolic content (TPC) and total flavonoid content (TFC) of the APM snacks as well raw material (flour blend) are depicted in Table 4. TPC was decreased significantly to $56.91 \mathrm{mg} / 100 \mathrm{~g}$ in extruded snacks from an initial value of $60.34 \mathrm{mg} / 100 \mathrm{~g}$ in flour blend, whereas a non-significant decrease was noticed in TFC from an initial value of $20.65 \mathrm{mg} / 100 \mathrm{~g}$ in flour blend to $19.29 \mathrm{mg} / 100 \mathrm{~g}$ in extruded snacks. It is very well documented that flavonoids are more heat stable than phenolics [45] because phenols are more susceptible to structural changes upon heating than flavonoids. In the present study, the significant loss of total phenolics can be attributed to the thermal degradation of free phenolics during extrusion cooking. Hu et al. (2018) also reported severe degradation of phenolic compounds at temperature $\geq 120{ }^{\circ} \mathrm{C}$ [46]. In contrast, flavonoids usually remain stable during extrusion cooking if the feed moisture content is higher, while the residence time and barrel temperature are on the lower side [47]. Therefore, the optimized conditions adopted during extrusion cooking in the present study were favorable for the retention of flavonoids. Patil et al. (2016) also reported that high feed moisture and less residence time restrict flavonoids' degradation [47].

\subsubsection{DPPH radical-scavenging activity (antioxidant activity).}

The antioxidant activity of phenolics may be related to their redox properties. They act as reducing agents; donate hydrogen-atoms, chelate metals; inhibit lipoxygenase, and scavenge free radicals [48]. The DPPH scavenging activity of both flour blend (be 89.93\%) as well as extruded (APM) snacks (89.74\%) (Table 4) was prominently higher with a non-significant difference which can be attributed to the presence of polyphenols and flavonoids having free 
radical scavenging activity $[49,50]$. About $100 \%$ scavenging activity of DPPH radicals was observed for brown almond skin by Siriwardhana et al. (2002) [48].

\subsubsection{Sensory evaluation.}

The overall acceptability score for the product was 8.2 on a 9-point hedonic scale (Table 4) which was ahead of what Yadav et al. (2014) reported for pearl millet-whey protein concentrate-based snacks. However, to validate its acceptability further, there is a need to conduct consumer acceptability tests in the future at a mass scale [10].

\section{Conclusions}

Nowadays, functional foods are in demand worldwide because consumers seek foods that offer health benefits beyond the nutritional value. The snack category is in no way an exception to this. Consumers eagerly seek snacks having additional health benefits. The present study was thus conducted to open up some options to develop functional snack food using defatted almond cake and pearl millet. After evaluating different test formulations, it was inferred that defatted almond meal and pearl millet flour in a proportion of 20:80 is the most feasible option if the development of ready-to-eat extruded snacks has better consumer acceptability is intended. Response surface methodology was adopted to study the effects of feed moisture content, screw speed, and barrel temperature on different product parameters. The generated regression models indicated that barrel temperature had a dominant effect on $\mathrm{ER}, \mathrm{BD}$, and hardness followed by screw speed, while as, WAI and WSI were dominantly affected by screw speed followed by moisture content. Process optimization was done by a design expert using a numerical optimization technique. The optimal solution selected based on the highest desirability value (0.88) suggested that $23 \%$ feed moisture content, 450rpm screw speed, and $120^{\circ} \mathrm{C}$ barrel temperature are the most desirable conditions to develop extruded snacks from mixed flour blend of DAC (20\%) and PM (80\%). The ranges of actual values obtained for different quality characteristics and overall acceptability results indicated that adopting extrusion technology could be promising if blended flour of defatted almond cake and pearl millet is explored to develop snacks. The proximate analysis reveals that in addition to its good nutritional profile, the product has a protein content of $15.45 \%$, indicating that largescale production of such types of snacks can be adopted as one of the options to reduce the huge burden of protein deficiency among the population, especially in children. If a child consumes $200 \mathrm{~g}$ of these snacks every day, it suffices $54 \%$ of total RDI $(0.75 \mathrm{~g} / \mathrm{kg}$ body weight/day) for his daily protein intake. Further, the findings of the bioactive analysis viz., $56.91 \mathrm{mg} / 100 \mathrm{~g}$ total phenolic content, $18.29 \mathrm{mg} / 100 \mathrm{~g}$ total flavonoids, and $89.74 \% \mathrm{DPPH}$ radical scavenging activity confirmed that a functional snack food could be developed from a mixed flour combination of defatted almond cake (20\%) and pearl millet (80\%) through extrusion cooking.

Overall, the present study's outcome has opened up a new window for the snack industry to develop functional snack foods from defatted almond cakes (DAC), which otherwise is a by-product of almond oil industries having no economic importance and is available at throwaway prices. However, keeping in view the fact that DAC has a good nutritional profile and contains an appreciable percentage of bioactive components, studies should be conducted in the near future to check its feasibility in the development of other types 
of products as well to diversify its value addition beyond the snack industry and to boost its profitable utilization.

\section{Funding}

This research received no external funding.

\section{Acknowledgments}

The authors greatly appreciate the cooperation extended by the Division of Post-Harvest Technology, Indian Agricultural Research Institute (IARI), New Delhi, and Hamdard Laboratories, Manesar, Gurgaon.

\section{Conflicts of Interest}

\section{The authors declare no conflict of interest}

\section{References}

1. Azeez, S.; Narayana, C.K.; Oberoi, H.S. Extraction and Utilisation of Bioactive Compounds from Agricultural Waste. Utilisation of Bioactive Compounds from Agricultural and Food Production Waste 2017, $5,127-158$.

2. Coman, V.; Teleky, B.-E.; Mitrea, L.; Martău, G.A.; Szabo, K.; Călinoiu, L.-F.; Vodnar, D.C. Chapter Five - Bioactive potential of fruit and vegetable wastes. In Adv. Food Nutr. Res., Toldrá, F., Ed. Academic Press: 2020; 91, 157-225, https://doi.org/10.1016/bs.afnr.2019.07.001.

3. Leonard, W.; Zhang, P.; Ying, D.; Fang, Z. Application of extrusion technology in plant food processing byproducts: An overview. Comprehensive Reviews in Food Science and Food Safety 2020, 19, 218-246, https://doi.org/10.1111/1541-4337.12514.

4. Prabha, K.; Ghosh, P.; S, A.; Joseph, R.M.; Krishnan, R.; Rana, S.S.; Pradhan, R.C. Recent development, challenges, and prospects of extrusion technology. Future Foods 2021, 3, 100019, https://doi.org/10.1016/j.fufo.2021.100019.

5. Li, S.; Liu, X.; Zhang, Y.; Liu, Q. Pilot-plant-scale test of cold-pressed oil extraction with twin-screw pressing for camellia seeds. Nongye Gongcheng Xuebao/Transactions of the Chinese Society of Agricultural Engineering 2014, 30, 300-308, https://doi.org/10.3969/j.issn.1002-6819.2014.19.036.

6. Siqueira, A.P.S.; Pacheco, M.T.B.; Naves, M.M.V. Nutritional quality and bioactive compounds of partially defatted baru almond flour. Food Science and Technology 2015, 35, 127-132, https://doi.org/10.1590/1678457X.6532.

7. Ramachandran, S.; Singh, S.K.; Larroche, C.; Soccol, C.R.; Pandey, A. Oil cakes and their biotechnological applications - A review. Bioresour. Technol. 2007, 98, 2000-2009, https://doi.org/10.1016/j.biortech.2006.08.002.

8. Nambiar, V.S.; Dhaduk, J.J.; Sareen, N.; Shahu, T.; Desai, R. Potential functional implications of pearl millet (Pennisetum glaucum) in health and disease. Journal of Applied Pharmaceutical Science 2011, 1, 62.

9. Coutinho, L.S.; Batista, J.E.R.; Caliari, M.; Soares Júnior, M.S. Optimization of extrusion variables for the production of snacks from by-products of rice and soybean. Food Science and Technology 2013, 33, 705712, https://doi.org/10.1590/S0101-20612013000400016.

10. Yadav, D.N.; Anand, T.; Navnidhi; Singh, A.K. Co-extrusion of pearl millet-whey protein concentrate for expanded snacks. Int. J. Food Sci. Tech. 2014, 49, 840-846, https://doi.org/10.1111/ijfs.12373.

11. Shadan, M.R.; Waghray, K.; Khoushabi, F. Formulation, preparation and evaluation of low-cost extrude products based on cereals and pulses. Food and Nutrition Sciences 2014, 5, https://doi.org/10.4236/fns.2014.514145.

12. Omwamba, M.; Mahungu, S.M. Development of a protein-rich ready-to-eat extruded snack from a composite blend of rice, sorghum and soybean flour. Food and Nutrition Sciences 2014, 5, https://doi.org/10.4236/fns.2014.514142. 
13. Alemayehu, H.; Emire, S.A.; Henry, C. Effects of extrusion process parameters on the quality properties of ready-to-eat pulse-based snacks. Cogent Food \& Agriculture 2019, 5, 1641903, https://doi.org/10.1080/23311932.2019.1641903.

14. Beigh, M.; Hussain, S.Z.; Qadri, T.; Naseer, B.; Raja, T.; Naik, H. Investigation of process and product parameters for physico-chemical properties of low Glycemic Index water chestnut and barley flour-based extruded snacks. Br. Food J. 2019, https://doi.org/10.1108/BFJ-01-2019-0001.

15. Food Safety and Standards Regulations, 2009. FSSAI regulations dealing with Microbiological parameters of food products https://old.fssai.gov.in/Portals/0/FSSAI\%20regulations.pdf.

16. Association of Official Analytical Chemists. Official methods of analysis of AOAC. International 17th edition; 2000, Gaithersburg, MD, USA.

17. Meng, X.; Threinen, D.; Hansen, M.; Driedger, D. Effects of extrusion conditions on system parameters and physical properties of a chickpea flour-based snack. Food Res. Int. 2010, 43, 650-658, https://doi.org/10.1016/j.foodres.2009.07.016.

18. Ciudad-Mulero, M.; Fernández-Ruiz, V.; Cuadrado, C.; Arribas, C.; Pedrosa, M.M.; De J. Berrios, J.; Pan, J.; Morales, P. Novel gluten-free formulations from lentil flours and nutritional yeast: Evaluation of extrusion effect on phytochemicals and non-nutritional factors. Food Chem. 2020, 315, 126175, https://doi.org/10.1016/j.foodchem.2020.126175.

19. Zhang, R.; Khan, S.A.; Chi, J.; Wei, Z.; Zhang, Y.; Deng, Y.; Liu, L.; Zhang, M. Different effects of extrusion on the phenolic profiles and antioxidant activity in milled fractions of brown rice. LWT 2018, 88, 64-70, https://doi.org/10.1016/j.lwt.2017.09.042.

20. Sahu, R.; Saxena, J. Screening of Total Phenolic and Flavonoid Content in Conventional and NonConventional Species of Curcuma. International Journal of Pharmaceutical Sciences Review and Research 2013, 21, 24-26.

21. Esfahlan, A.J.; Jamei, R. Properties of biological activity of ten wild almond (Prunus amygdalus L.) species. Turkish Journal of Biology 2012, 36, 201-209.

22. Samuel, F.O.; Ishola, O.R.; Otegbayo, B.O. Nutritional and Sensory Evaluation of Rice-Based Masa Enriched with Soybean and Crayfish. Food and Nutrition Sciences 2015, 6, 234, https://doi.org/10.4236/fns.2015.62024.

23. Fadlallah, O.; Tinay, A.; Babiker, E. Effect of fermentation on biochemical characteristics of sorghum flour supplemented with chickpea flour. Journal of Applied Sciences Research 2010, 6, 860-865.

24. Sawant, A.A.; Thakor, N.J.; Swami, S.B.; Divate, A.D.; Vidyapeet, B.S.K.K. Physical and sensory characteristics of ready-to-eat food prepared from finger millet based composite mixer by extrusion. Agricultural Engineering International: CIGR Journal 2012, 15, 100-105.

25. Köksel, H.; Ryu, G.-H.; Basman, A.; Demiralp, H.; Ng, P.K.W. Effects of extrusion variables on the properties of waxy hulless barley extrudates. Food / Nahrung 2004, 48, 19-24, https://doi.org/10.1002/food.200300324.

26. Salata, C.d.C.; Leonel, M.; Trombini, F.R.M.; Mischan, M.M. Extrusion of blends of cassava leaves and cassava flour: physical characteristics of extrudates. Food Science and Technology 2014, 34, 501-506, https://doi.org/10.1590/1678-457x.6337.

27. Ding, Q.-B.; Ainsworth, P.; Plunkett, A.; Tucker, G.; Marson, H. The effect of extrusion conditions on the functional and physical properties of wheat-based expanded snacks. J. Food Eng. 2006, 73, 142-148, https://doi.org/10.1016/j.jfoodeng.2005.01.013.

28. Filli, K.B.; Nkama, I.; Jideani, V.A.; Abubakar, U.M. The effect of extrusion conditions on the physicochemical properties and sensory characteristics of millet-cowpea based fura. European Journal of Nutrition \& Food Safety 2012, 1-23.

29. Altan, A.; McCarthy, K.L.; Maskan, M. Evaluation of snack foods from barley-tomato pomace blends by extrusion processing. J. Food Eng. 2008, 84, 231-242, https://doi.org/10.1016/j.jfoodeng.2007.05.014.

30. Hashemi, N.; Mortazavi, S.A.; Milani, E.; Tabatabai Yazdi, F. Microstructural and textural properties of puffed snack prepared from partially deffated almond powder and corn flour. J. Food Process. Preserv. 2017, 41, e13210, https://doi.org/10.1111/jfpp.13210.

31. Nath, A.; Chattopadhyay, P.K. Effect of process parameters and soy flour concentration on quality attributes and microstructural changes in ready-to-eat potato-soy snack using high-temperature short time air puffing. LWT - Food Science and Technology 2008, 41, 707-715, https://doi.org/10.1016/j.lwt.2007.05.001.

32. Oikonomou, N.A.; Krokida, M.K. Literature Data Compilation of WAI and WSI of Extrudate Food Products. Int. J. Food Prop. 2011, 14, 199-240, https://doi.org/10.1080/10942910903160422. 
33. Rodríguez-Miranda, J.; Ruiz-López, I.I.; Herman-Lara, E.; Martínez-Sánchez, C.E.; Delgado-Licon, E.; Vivar-Vera, M.A. Development of extruded snacks using taro (Colocasia esculenta) and nixtamalized maize (Zea mays) flour blends. LWT - Food Science and Technology 2011, 44, 673-680, https://doi.org/10.1016/j.lwt.2010.06.036.

34. Day, L.; Swanson, B.G. Functionality of Protein-Fortified Extrudates. Comprehensive Reviews in Food Science and Food Safety 2013, 12, 546-564, https://doi.org/10.1111/1541-4337.12023.

35. Grasso, S. Extruded snacks from industrial by-products: A review. Trends Food Sci. Technol. 2020, 99, 284294, https://doi.org/10.1016/j.tifs.2020.03.012.

36. Li, M.; Lee, T.-C. Relationship of the Extrusion Temperature and the Solubility and Disulfide Bond Distribution of Wheat Proteins. J. Agric. Food Chem. 1997, 45, 2711-2717, https://doi.org/10.1021/jf960703t.

37. Kumar, A.; Samuel, D.V.K.; Jha, S.; Sinha, J.P. Twin Screw Extrusion of Sorghum and Soya Blends: A Response Surface Analysis. Journal of Agricultural Science and Technology 2015, 17, 649-662.

38. Alam, M.S.; Pathania, S.; Kumar, S.; Sharma, A. Studies on storage stability of carrot pomace-chickpea incorporated rice based snacks. Agric Res $J$ 2015, 52, 73-79, https://doi.org/10.5958/2395146X.2015.00066.6.

39. Keawpeng, I.; Charunuch, C.; Roudaut, G.; Meenune, M. The optimization of extrusion condition of Phatthalung Sungyod rice extrudate: a preliminary study. 2014, 21, 2299-2304.

40. Divate, A.; Sawant, A.A.; Thakor, N.J. Effect of extruder temperature on functional characteristics of finger millet [Eleusine coracana (L) Gaertn] based extrudates. Global Science Research Journals 2015, 3, 239-246.

41. Alonso, R.; Rubio, L.A.; Muzquiz, M.; Marzo, F. The effect of extrusion cooking on mineral bioavailability in pea and kidney bean seed meals. Anim. Feed Sci. Technol. 2001, 94, 1-13, https://doi.org/10.1016/S03778401(01)00302-9.

42. Singh, S.; Gamlath, S.; Wakeling, L. Nutritional aspects of food extrusion: a review. Int. J. Food Sci. Tech. 2007, 42, 916-929, https://doi.org/10.1111/j.1365-2621.2006.01309.x.

43. Singh, N.; Meenu, G.; Sekhar, A.; Jayanthi, A. Evaluation of antimicrobial and anticancer properties of finger millet (Eleusine coracana) and pearl millet (Pennisetum glaucum) extracts. The Pharma Innovation 2015, 3, 82.

44. Barreira, J.C.M.; Ferreira, I.C.F.R.; Oliveira, M.B.P.P.; Pereira, J.A. Antioxidant activity and bioactive compounds of ten Portuguese regional and commercial almond cultivars. Food Chem. Toxicol. 2008, 46, 2230-2235, https://doi.org/10.1016/j.fct.2008.02.024.

45. Elhamirad, A.H.; Zamanipoor, M.H. Thermal stability of some flavonoids and phenolic acids in sheep tallow olein. Eur. J. Lipid Sci. Technol. 2012, 114, 602-606, https://doi.org/10.1002/ejlt.201100240.

46. Hu, Z.; Tang, X.; Zhang, M.; Hu, X.; Yu, C.; Zhu, Z.; Shao, Y. Effects of different extrusion temperatures on extrusion behavior, phenolic acids, antioxidant activity, anthocyanins and phytosterols of black rice. RSC Advances 2018, 8, 7123-7132, https://doi.org/10.1039/C7RA13329D.

47. Patil, S.S.; Varghese, E.; Rudra, S.G.; Kaur, C. Effect of extrusion processing on phenolics, flavonoids and antioxidant activity of millets. International Journal of Food and Fermentation Technology 2016, 6, 177 , https://doi.org/10.5958/2277-9396.2016.00040.4.

48. Siriwardhana, S.S.K.W.; Shahidi, F. Antiradical activity of extracts of almond and its by-products. J. Am. Oil Chem. Soc. 2002, 79, 903-908, https://doi.org/10.1007/s11746-002-0577-4.

49. Lemos, M.R.B.; Siqueira, E.M.d.A.; Arruda, S.F.; Zambiazi, R.C. The effect of roasting on the phenolic compounds and antioxidant potential of baru nuts [Dipteryx alata Vog.]. Food Res. Int. 2012, 48, 592-597, https://doi.org/10.1016/j.foodres.2012.05.027.

50. Arribas, C.; Cabellos, B.; Cuadrado, C.; Guillamón, E.; Pedrosa, M.M. The effect of extrusion on the bioactive compounds and antioxidant capacity of novel gluten-free expanded products based on carob fruit, pea and rice blends. Innov. Food Sci. Emerg. Technol. 2019, 52, 100-107, https://doi.org/10.1016/j.ifset.2018.12.003. 